3 Research Square

\title{
Extremely wet summer events enhance permafrost thaw for multiple years in Siberian tundra
}

\section{Rúna Magnússon ( $\nabla$ runa.magnusson@wur.nl)}

Wageningen University \& Research https://orcid.org/0000-0003-2254-2612

\section{Alexandra Hamm}

Department of Physical Geography, Stockholm University

\section{Sergey V. Karsanaev}

Institute for Biological Problems of the Cryolithozone, Siberian Branch of the Russian Academy of

Sciences

Juul Limpens

Wageningen University

\section{David Kleijn}

Plant Ecology \& Nature Conservation, Wageningen University \& Research https://orcid.org/0000-00032500-7164

\section{Andrew Frampton}

Department of Physical Geography, Stockholm University

\section{Trofim C. Maximov}

Institute for Biological Problems of the Cryolithozone, Siberian Branch of the Russian Academy of

Sciences

monique heijmans

Wageningen University

\section{Article}

Keywords: Permafrost, precipitation, thaw depth, active layer thickness, soil thermal hydrology modelling, Siberian lowland tundra, Arctic climate change, extreme event

Posted Date: May 27th, 2021

DOl: https://doi.org/10.21203/rs.3.rs-512675/v1

License: (9) (1) This work is licensed under a Creative Commons Attribution 4.0 International License. Read Full License 
Version of Record: A version of this preprint was published at Nature Communications on March 23rd, 2022. See the published version at https://doi.org/10.1038/s41467-022-29248-x. 
1 Extremely wet summer events enhance permafrost thaw for multiple years in

2 Siberian tundra

3 Rúna Í. Magnússon', Alexandra Hamm², Sergey V. Karsanaev', Juul Limpens', David

4 Kleijn', Andrew Frampton', ${ }^{2,3}$ Trofim C. Maximov' and Monique M. P. D. Heijmans'.

5 1. Plant Ecology and Nature Conservation Group, Wageningen University \&

6 Research, Wageningen, The Netherlands

2. Department of Physical Geography, Stockholm University, Stockholm, Sweden

3. Bolin Centre for Climate Research, Stockholm University, Stockholm, Sweden

4. Institute for Biological Problems of the Cryolithozone, Siberian Branch of the Russian Academy of Sciences, Yakutsk, Russia

\section{Abstract}

Permafrost thaw can accelerate climate warming by releasing carbon from previously frozen soil in the form of greenhouse gases. Summer precipitation extremes have been proposed to increase permafrost thaw, but the magnitude and duration of this effect are poorly understood. Here we present empirical evidence showing that one extremely wet summer $(+100 \mathrm{~mm} ; 120 \%$ increase relative to average summer precipitation) enhances thaw depth by up to $35 \%$ and prolonged the thaw period in a controlled irrigation experiment in an ice-rich Siberian tundra site. The effect persisted over two subsequent summers, demonstrating a carry-over effect of extremely wet summers. Using soil thermal hydrological modelling, we show that precipitationinduced increases in thaw are most pronounced during warm summers with midsummer precipitation peaks. Our results suggest that, with summer precipitation and 
temperature both increasing in the Arctic, permafrost will likely degrade and disappear faster than is currently anticipated based on rising air temperatures alone.

\section{Keywords}

Permafrost, precipitation, thaw depth, active layer thickness, soil thermal hydrology modelling, Siberian lowland tundra, Arctic climate change, extreme event

\section{Main}

$\underline{\text { Introduction }}$

Permafrost has been degrading rapidly and ubiquitously in response to Arctic warming $^{1-6}$. Climate models suggest that $24 \%$ (RCP2.6) to $70 \%$ (RCP8.5) of near surface permafrost may disappear in the coming 80 years. This could result in the release of tens to hundreds Gt carbon into the atmosphere, further enhancing climate warming ${ }^{7}$. Although highly responsive to air temperature ${ }^{1,8,9}$, permafrost degradation rates also depend on other climatic, soil physical, hydrological and vegetation related factors $^{10-14}$. Recent model studies suggest that precipitation increases may enhance permafrost degradation as much as air temperature ${ }^{15}$, but the magnitude and duration of the effect of precipitation extremes are poorly understood. We set out to quantify the effect of extreme summer precipitation on permafrost thaw in a field experiment to contribute to improved projections of future permafrost degradation.

Arctic precipitation is anticipated to increase ${ }^{16,17}$ by up to $60 \%$ locally (RCP8.5) during the coming 80 years ${ }^{17}$ and to increasingly shift from snow to rain due to rising air temperature ${ }^{18}$. In addition, increases in the seasonal variability of precipitation, particularly in summer ${ }^{17}$, imply that extreme rain events may occur more frequently. The impact of summer precipitation extremes on permafrost thaw remains poorly 
understood. Infiltrating rain can enhance thaw ${ }^{19-22}$, either directly if the temperature of rainwater exceeds that of the soil ${ }^{15,22,23}$ or indirectly by increasing soil thermal conductivity ${ }^{23-25}$. On the other hand, increased precipitation may also slow down warming of cold permafrost soils ${ }^{20,26}$ through increased soil thermal capacity of wetter soils ${ }^{23-25}$. Lastly, higher soil moisture content increases the thermal energy required during freeze-thaw processes and evaporation ${ }^{23-25}$. The balance between these various processes determines the net effect of summer precipitation on permafrost thaw and may depend on air temperatures and seasonal timing ${ }^{23}$, suggesting a potentially important interactive effect between rising summer temperatures and changing precipitation patterns in the future Arctic. Lastly, it is conceivable that the effects of extreme summer precipitation can persist over multiple years, for instance through increased soil ice contents in winters following extremely wet summers ${ }^{21}$ or through structural alteration of the upper permafrost layer following enhanced seasonal thaw ${ }^{27}$. The magnitude and duration of potential carry-over effects of extreme summer precipitation are presently unknown.

Here, we assess the impact of one extremely wet summer on permafrost thaw in a controlled field irrigation experiment (10 irrigated, 10 control plots) in the north-eastern Siberian lowland tundra over three summers (fig. 5). This region is characterized by thick, ice-rich permafrost ${ }^{10,28}$ and a distinctly continental climate with warm summers ${ }^{29}$, giving it the potential for substantial permafrost degradation. The irrigation treatment $(+100 \mathrm{~mm})$ was set to mimic an extremely wet summer for this ecosystem $(191 \mathrm{~mm}$ compared to $81 \mathrm{~mm}$ on average in June-August ${ }^{30}$ ). To further explore dependence of precipitation effects on air temperature and seasonal timing, we used a physicallybased numerical model accounting for necessary thermal and hydrological processes in permafrost regions (ATS) ${ }^{31}$. We conditioned the model using field measurements 
72 and then conducted a model-based investigation of thaw depth under various 73 precipitation and temperature scenarios.

$74 \quad$ Results

75 Field Irrigation Experiment 
(a) Daily air temperature summer season
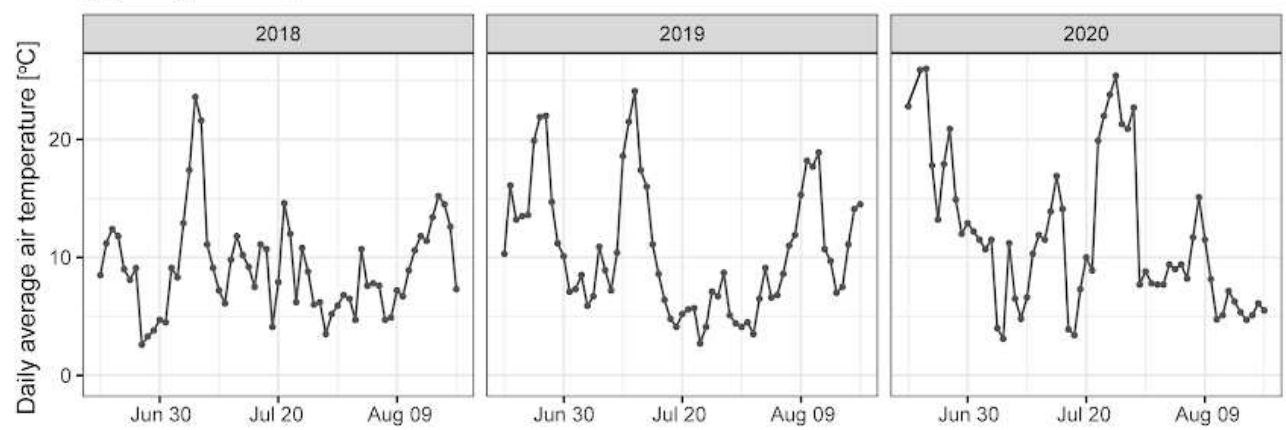

(b) Daily total precipitation summer season
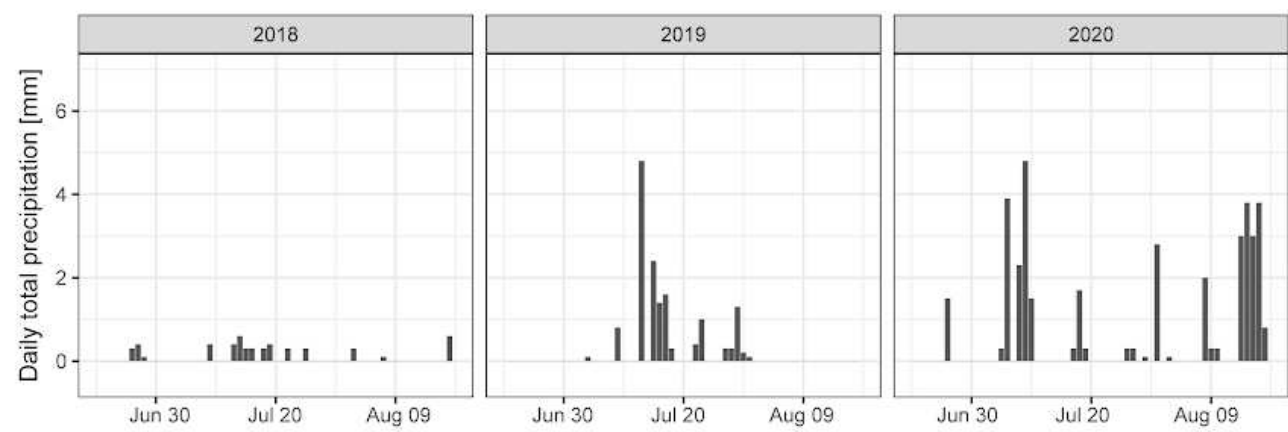

(c) Development of Thaw Depth over summer season
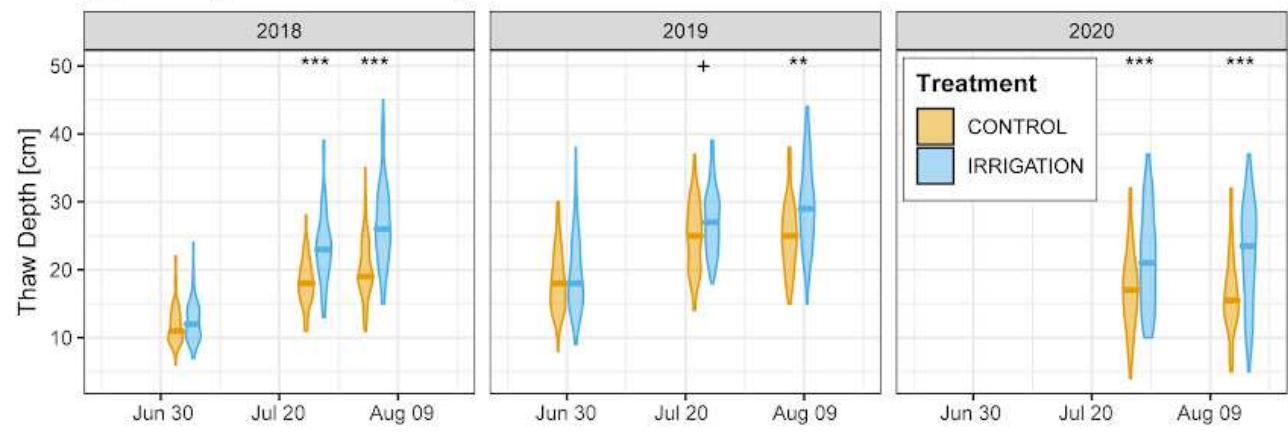

(d) Development of Water Table over summer season
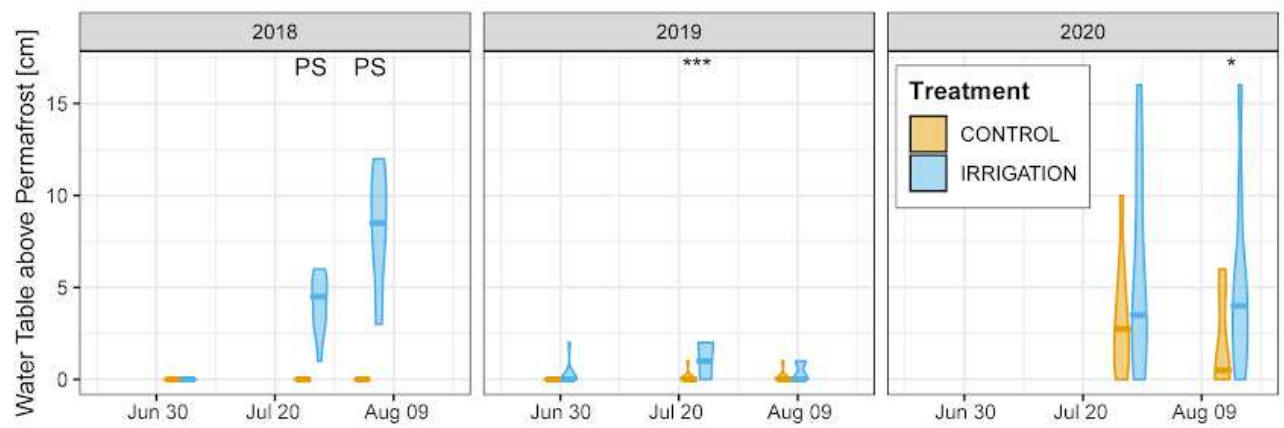

(e) Development of Soil Moisture over summer season
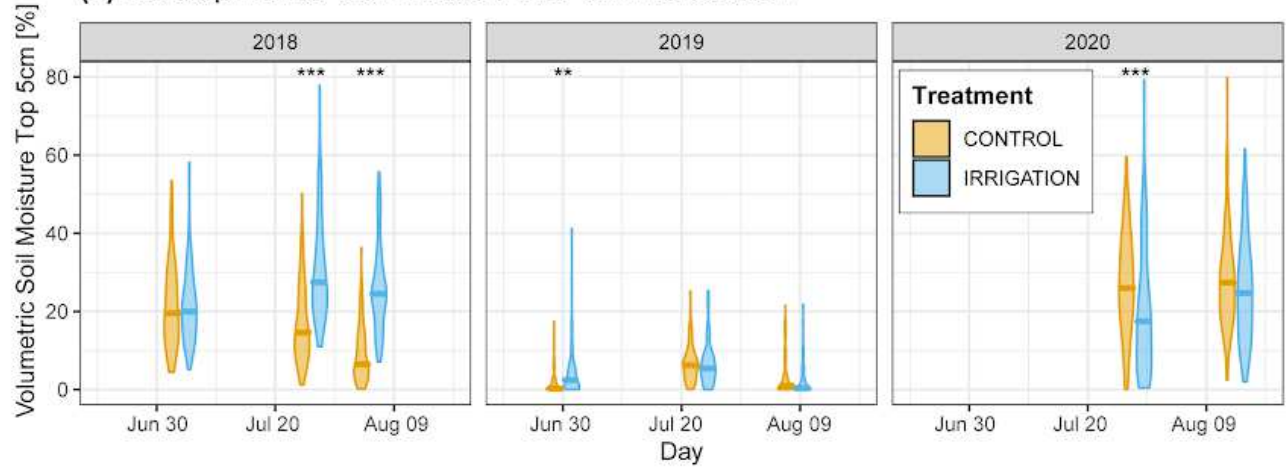
Figure 1) Abiotic conditions in control (orange) and irrigated (blue) plots during irrigation (2018) and subsequent summers without irrigation (2019 \& 2020). The earliest 2018 measurements were taken before irrigation started. a) Average daily air temperature and b) total daily precipitation recorded in Chokurdakh (WMO station code 21649). c) Thaw depth (n $=90$ per violin). $\boldsymbol{d}$ ) Water table above permafrost in plot centres ( $n=10$ per violin). e) Volumetric soil moisture content of the topsoil (5cm depth) ( $n=90$ per violin). In c-e), violin length represents data range and violin width represents the probability density of the data distribution. Horizontal bars indicate group medians. Symbols above plots represent significant Tukey contrasts between irrigation and control per measurement date $(+:<0.1$, *: $\left.p<0.05,{ }^{* *}:<0.01,{ }^{* * *}: p<0.001\right) .{ }^{*} P S^{*}$ indicates perfect separation (see d), in which case no p-values could be derived. Model specifications and estimated marginal means are in Supplementary Results I.

We found that extreme summer precipitation $(100 \mathrm{~mm},+120 \%)$ increased permafrost thaw depth substantially over multiple years. During the summer of irrigation, thaw depths in irrigated plots gradually increased relative to control sites up to a $32 \%(+6.3$ $\mathrm{cm}$ ) difference in early August (fig. 1c). The magnitude of this effect aligns with that observed in Alaskan permafrost ecosystems, where a $10 \mathrm{~mm}$ increase in precipitation was estimated to result in a $0.7 \mathrm{~cm}$ increase in active layer thickness ${ }^{19}$. In addition, extreme summer precipitation increased the volumetric moisture content of the topsoil relative to control plots following irrigation (fig. 1e) and led to accumulation of a water table above the permafrost (fig. 1d). The following summers, thaw depths were still higher in irrigated plots than control plots in early August, with differences of $4.3 \mathrm{~cm}$ $(+18 \%)$ in 2019 and $5.6 \mathrm{~cm}(+35 \%)$ in 2020 . Warm temperatures during the years after irrigation (fig. 1a) may have contributed to the sustained increase in thaw depth. Higher topsoil moisture in early summer 2019 and a continued increase in water tables on top of the permafrost (fig. 1d-e) strongly suggest that added precipitation (partially) freezes 
up and is released in subsequent summers. Increased moisture content was observed 104 in the topsoil as well as the subsoil (fig. S4) and is in line with earlier observational studies $^{21,32}$. Apart from direct water input from irrigation, increased thaw depths in 106 irrigated sites may have caused lateral flow, reduced evaporation due to deeper 107 infiltration or promoted release of moisture from melting of excess ground ice ${ }^{21}$, further contributing to higher water tables (fig. 1d).

Substantial variation among observations, even within plots, suggests a high degree of spatial heterogeneity in thaw depths and soil moisture (fig. 1c-e). Similarly, measurements varied among individual years. In the dry summer of 2018, no water

112 tables were observed in control plots, whereas water tables in irrigated plots varied 113 between 3 and $12 \mathrm{~cm}$ in early August. In 2019, soil moisture was very low in all plots and water tables were generally absent (fig. 1e), likely caused by hot and dry meteorological conditions in early summer 2019 (fig. 1a-b). In the wetter summer of 2020, higher water tables were observed, and topsoils in irrigated plots were drier than

117 control plots, presumably related to the deeper thaw depth (fig. 1c). Despite this spatio118 temporal variability, irrigated plots still displayed more frequent and higher water tables 119 and deeper thaw. 
(a) Model Representation of Field-Measured Thaw Depths
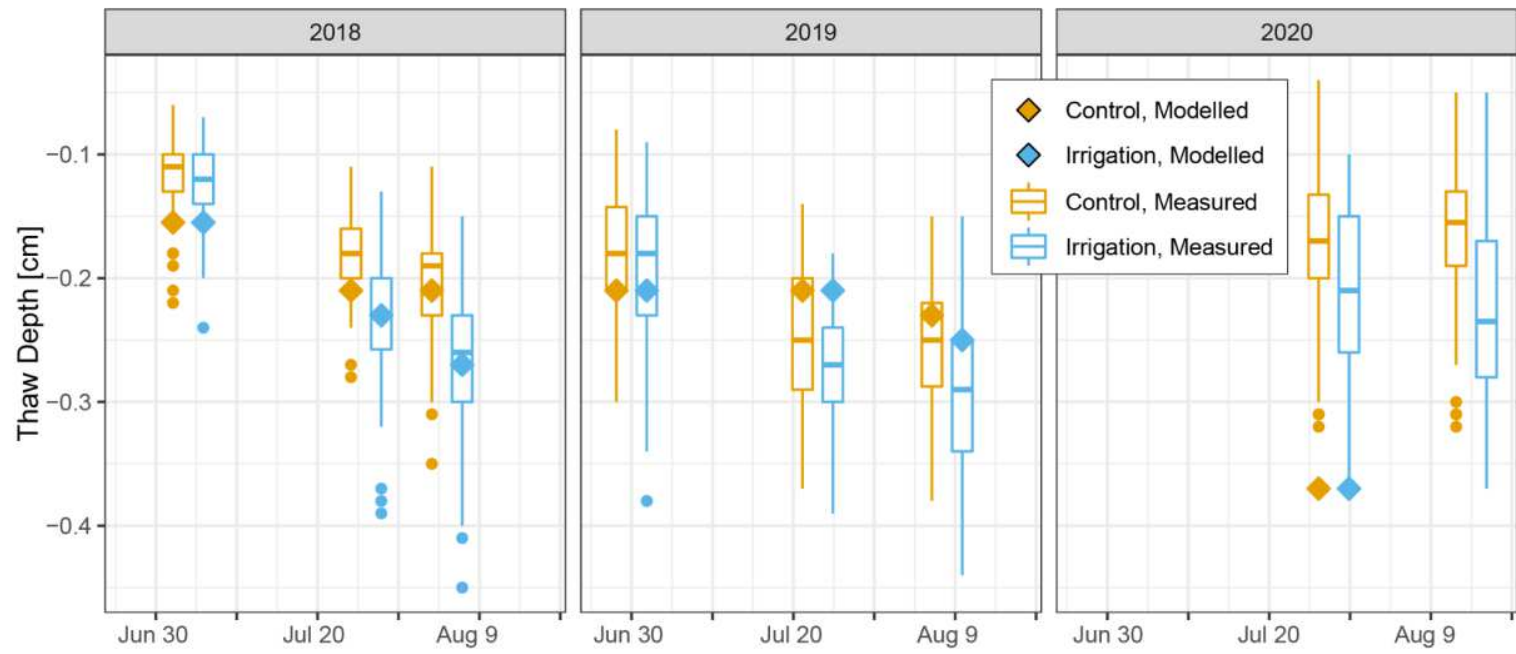

(b) Modelled difference in Thaw Depth between irrigation and control scenario
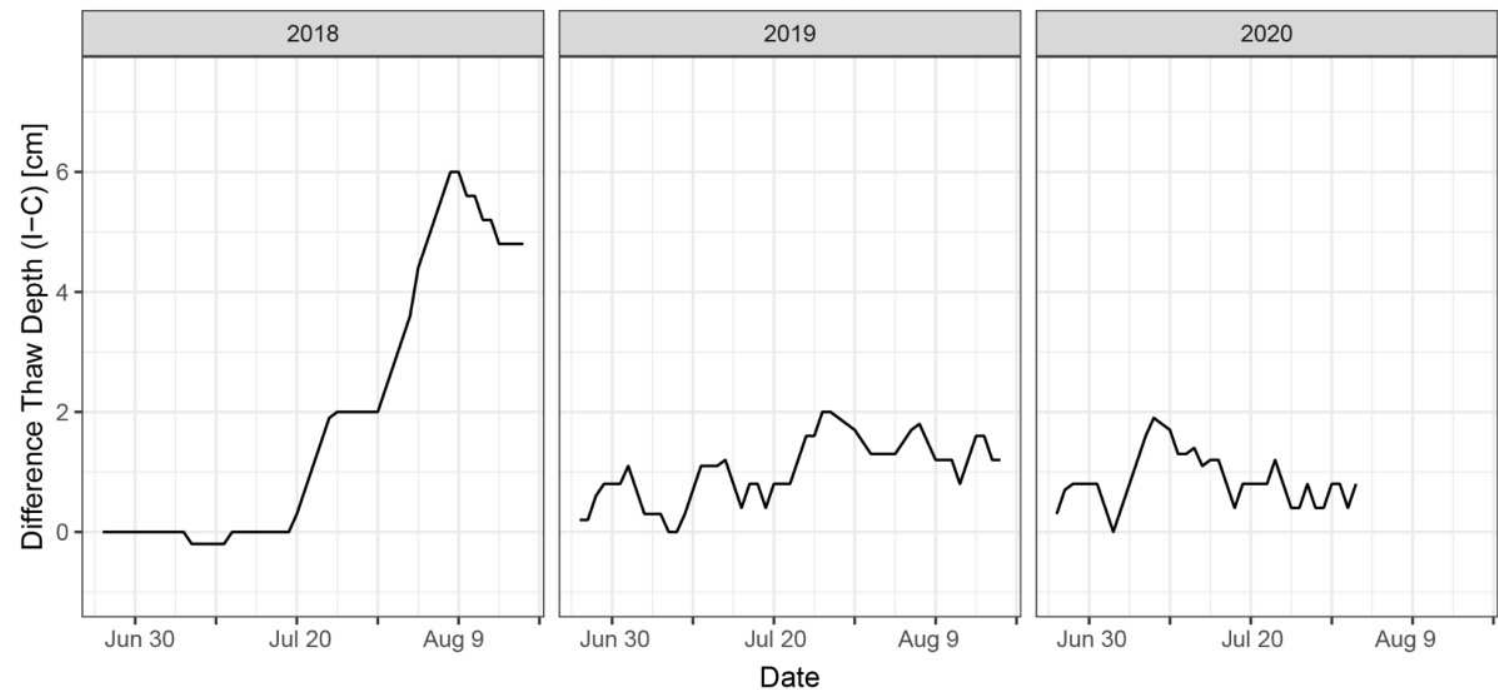

Figure 2) a) Modelled and measured thaw depth for 2018-2020 with mean field measurement values. Boxplots for measured thaw depths represent all individual measurements in irrigated (blue) and control (orange) plots $(n=90$ per box).

b) Modelled difference between irrigation and control scenario, smoothed with a 5-day moving average. Modelled data is only available up until the end of the meteorological record (July 31st 2020).

127 A physically-based numerical model (the Advanced Terrestrial Simulator, ATS v. $088^{31}$ ) driven by site meteorological data was used to provide mechanistic insight in support of the field experiment. ATS was configured for local site conditions and conditioned for active representation of thaw dynamics using measurements from the 131 irrigation experiment (Supplementary Methods III-V). Modelled thaw depth closely 
followed field measured thaw depths across both scenarios representing control and irrigated plots during the year of irrigation (fig. 2). Representation of site-measured soil temperature and moisture content was generally accurate (fig. S7-S8). Modelled effects of irrigation on thaw depth were smaller than those observed in the field, indicating that the model-based results are conservative estimates.

Apart from differences in instantaneous thaw depths, the model yielded a $5 \mathrm{~cm}$ difference in active layer thickness (ALT, the maximum end-of-season thaw depth) in 2018. Such an effect roughly corresponds to that of a $1.7^{\circ} \mathrm{C}$ increase in mean summer temperature (fig. S14) ${ }^{33}$. Modelled ALTs (control: $37 \mathrm{~cm}$, irrigation: $42 \mathrm{~cm}$ ) closely resemble typical ALTs for this region ${ }^{33}$. An 8-day delay in complete freeze-up was modelled under irrigation compared to the control scenario (fig. S6). Model results are in line with the experiment, showing sustained small increases in thaw depth of up to 2cm in the irrigated scenario in 2019 and 2020 and a 2-day delay in freeze-up in 2019. Modelled thaw depths for 2020 were larger than measured thaw depths, likely in response to very warm summer air temperatures (fig. 1a).

Model results suggest that increased soil moisture after irrigation remained in the soil during autumn freeze-up, resulting in increased ice content throughout the soil profile in winter in irrigated sites (fig. S11). Subsequent release of soil moisture in following summers (fig. S6, S8) likely mediated the observed carry-over effect. Irrigation increased subsoil temperatures (fig. S6) and thaw depth both directly through input of heat from rainwater with a higher temperature than the subsoil (fig. S10) and indirectly through increased thermal conductivity in wetter soil (fig. S11). In contrast, colder topsoils were observed under extreme precipitation, both in model results and field measurements (fig. S6, S8), as a result of evaporative cooling (fig. S9) ${ }^{26,34}$. 
(a) Active Layer Thickness - Overall Increases

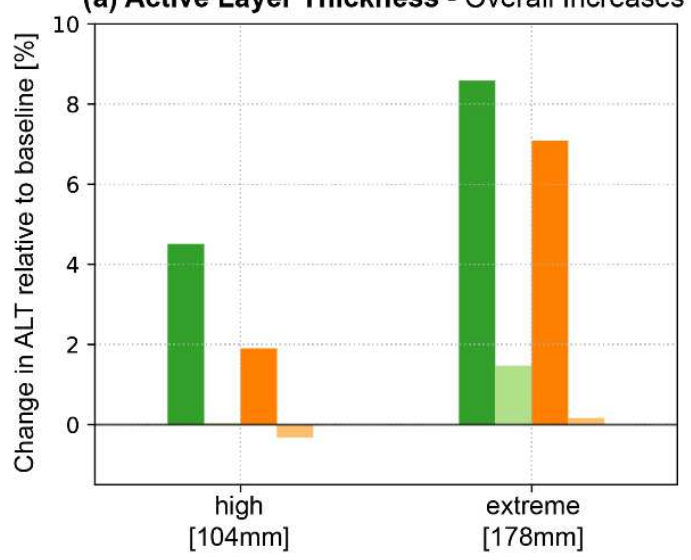

(c) Active Layer Thickness - Monthly Increases

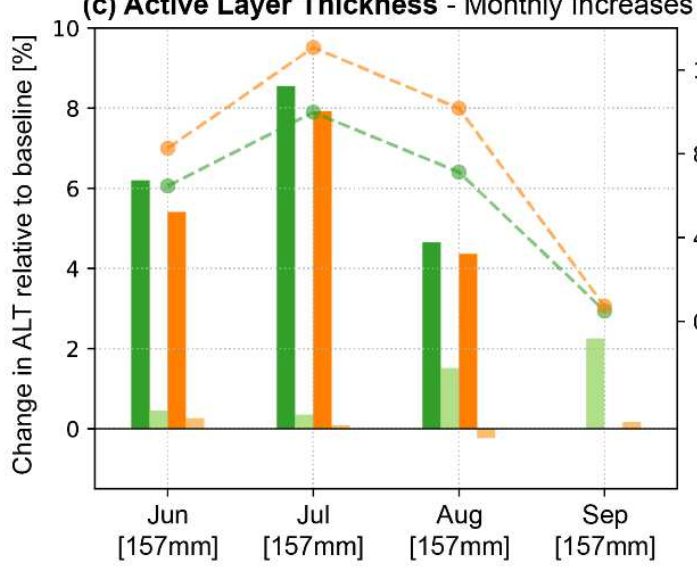

(b) Freeze-up Timing - Overall Increases

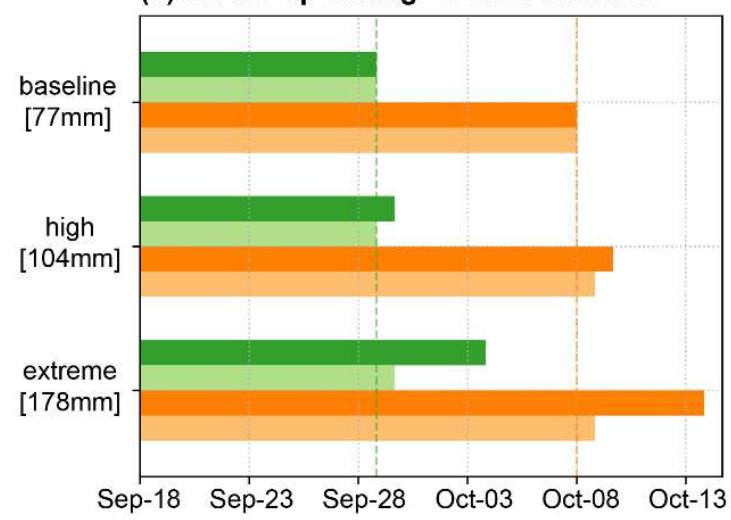

(d) Freeze-up Timing - Monthly Increases

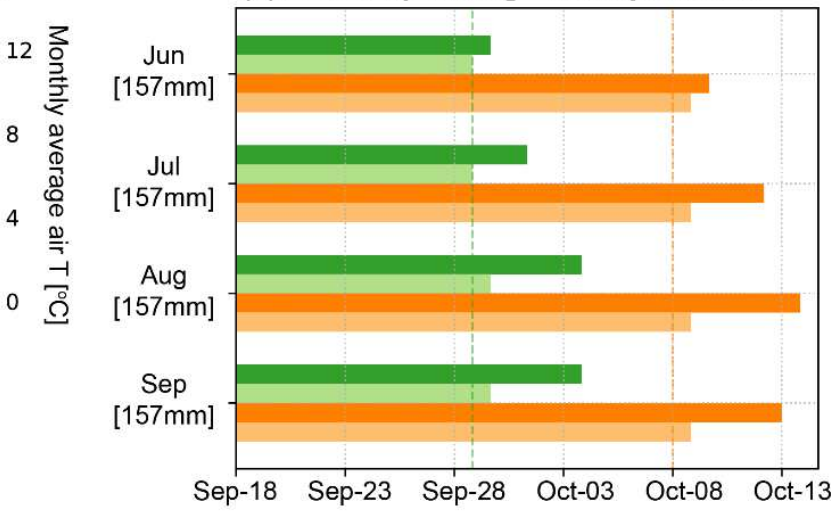

Figure 3) Effect of precipitation scenarios on active layer dynamics. Results are reported for average (green) and warm (orange) summers and for the year of altered precipitation (YO, dark shades) and the year after, with baseline conditions (Y1, light shades). a) Modelled percentual difference in active layer thickness (ALT) under increased June - August (JJA) precipitation. b) Modelled timing of complete freeze-up of the soil column under JJA increased precipitation. c) Modelled percentual difference in $A L T$ under increased precipitation in particular months. Dashed lines indicate mean temperature during the month of modelled additional precipitation in average (green) and warm (orange) summers. d) Modelled timing of complete freeze-up under increased precipitation in particular months. In a \& c, changes (\%) in $A L T$ are reported relative to baseline precipitation under the corresponding temperature scenario (average or warm summer). Positive changes percentages indicate an increase in $A L T$. 
The conditioned model was used to analyse active layer thickness and freeze-up timing under precipitation and temperature scenarios based on site meteorological data (fig. S3). The magnitude of ALT increase under increased summer precipitation depended on timing of precipitation events relative to air temperature dynamics (fig 3c). Under average summer temperature $\left(T_{\text {ag, }, \mathrm{A}}=7.9 \circ \mathrm{C}\right)$, baseline $A L T$ was $27.2 \mathrm{~cm}$, while extreme precipitation increased it to $29.6 \mathrm{~cm}$. In a warm summer $\left(\mathrm{T}_{\text {ag, } \mathrm{sA}}=\right.$ 10.6.C), ALT was $46.6 \mathrm{~cm}$ under baseline conditions and $50.3 \mathrm{~cm}$ under extreme precipitation, indicating a larger net increase in warm summers. Both in average and warm summers, July precipitation had the largest effect on ALT, whereas increased precipitation in early and late summer had a smaller effect. These results suggest that the timing of precipitation events within the summer season plays a major role in thawdepth evolution. High precipitation in September did not affect ALT in the same year because freeze-up had already started in September (fig. S12-S13). However, August and September precipitation have the strongest influence on freeze-up duration; the later precipitation is added to the system, the longer freeze-up is postponed. Delays of 6 to 7 days were found for the extreme precipitation scenario and August and September precipitation scenarios both in average and in warm summers (fig. 3b,d). This is likely explained by higher heat capacity and increased release of latent heat in wetter soils during freezing, both of which delay autumn freeze-up ${ }^{22,23}$. These results indicate that extreme summer precipitation not only leads to deeper thaw, but also extends the period over which soils are biologically active. Additionally, they demonstrate that the effect of summer precipitation extremes depends on their timing and is largest during warm conditions.

Model results indicate that effects of summer precipitation extremes additionally vary among seasons and soil strata. Soil temperature changes were most evident in 
subsequent winters (fig. S12-S13). Warming effects were visible in the topsoil in autumn and early winter due to delayed freeze-up, especially under late summer precipitation, which resulted in increases in topsoil temperature of up to 2 degrees during early winter. Modelled winter subsoil temperatures were lower than in the baseline scenario likely due to increased thermal conductivity under higher ice-content (fig. S11). In spring, increased ice content impedes warming of the topsoil through latent heat consumption (fig. S12-S13). Similar changes in winter soil temperature following extreme precipitation were evident from field observations (fig. S8). Soil temperatures in subsequent summers quickly returned to baseline conditions and only small differences in thaw depth persisted (fig. S12-S13). Marginal delays in freeze-up persisted in subsequent summers, mostly under late summer and extreme precipitation and under warmer summer temperatures (fig. 3b,d, S12-S13). The effects of extreme summer precipitation on the soil thermal regime in ice-rich Siberian lowland tundra are summarized in fig. 4.

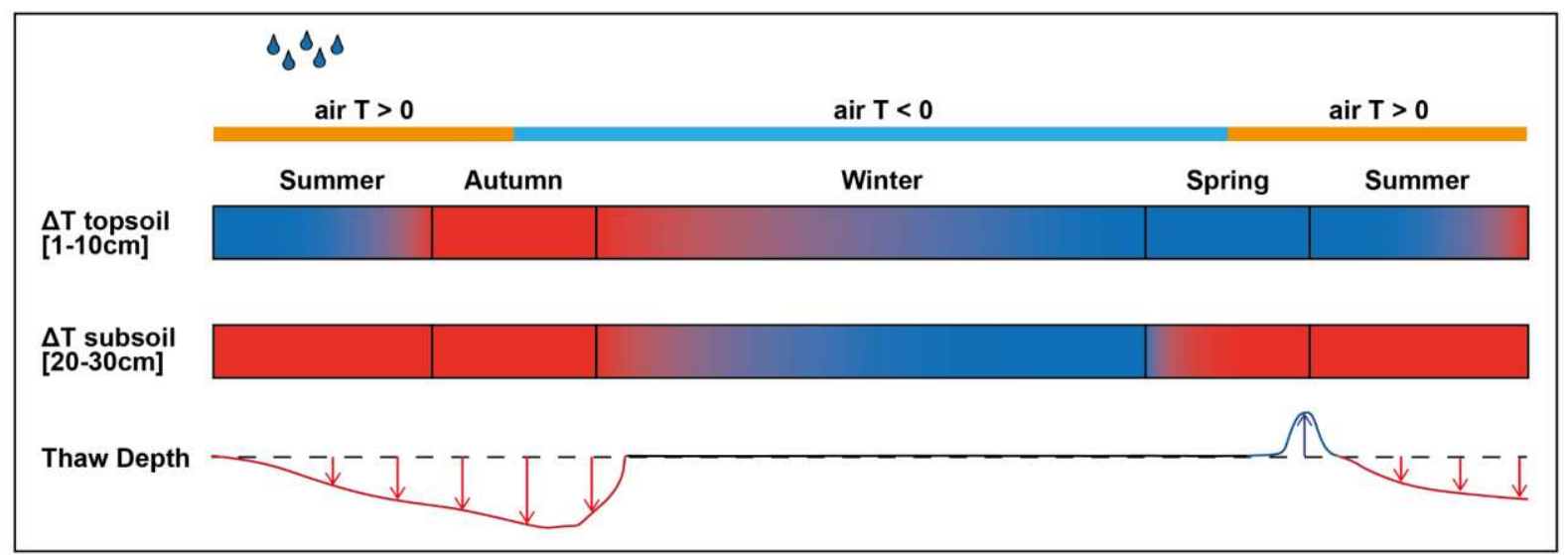

Figure 4) Conceptual diagram of the effect of extreme summer precipitation on the soil thermal regime throughout the year and the following summer season, based on field observations and model results (fig. 1, S8, S12-S13). The top two bars represent temperature differences in the organic topsoil $(0-10 \mathrm{~cm}$ depth) and mineral subsoil $(20-30 \mathrm{~cm}$ depth) relative to a situation with average summer precipitation. Red colours indicate warmer temperatures under 
extreme precipitation and blue colours represent colder temperatures under extreme precipitation. The bottom line represents differences in thaw depth compared to a situation with average summer precipitation, with red downward arrows representing deeper thaw, blue upward arrows indicating shallower thaw and black colours representing no thaw depth (fully frozen soil). The effects of extreme summer precipitation vary by depth, with topsoils exhibiting evaporative cooling and persistent warming throughout autumn and early winter, whereas subsoils show warming in summer and cooling in winter.

\section{Discussion}

Combined dynamics of summer precipitation and air temperature determine permafrost thaw dynamics

Our study provides the first field-based, causal evidence of the adverse effect of extreme summer precipitation on permafrost thaw and magnitude and duration thereof. We found a substantial increase in thaw depth (up to 35\%) under irrigation, which persisted for several years. Modelling analysis showed that increased precipitation warmed the soil through direct input of warmer rainwater into colder soils (advective heat transfer) and increased heat conduction in summer. Furthermore, the effect of summer precipitation on permafrost thaw depended on air temperature during precipitation events. Modelled increases in ALT were largest when precipitation was increased during warmer mid-summer conditions (fig. 3c). While the percentage increase in active layer thickness (ALT) was comparable in summers with average and high temperatures (fig. 3a, up to 8.5\%), net increases were larger under a combined increase in precipitation and air temperature (up to $2.3 \mathrm{~cm}$ in average and $3.7 \mathrm{~cm}$ and warm summers). These increases may be larger in reality, since the model yielded conservative estimates of the effects of irrigation on permafrost thaw (fig. 2). 
Interactive effects with temperature may be attributed to increased heat transfer into the soil with infiltration of rainwater, since the temperature of rainwater tends to follow ambient air temperature ${ }^{22}$. Larger temperature gradients between soil and soil surface in warmer periods may also enhance conductive heat transport into the soil ${ }^{23}$. Late summer precipitation had little to no effect on ALT in the same season, but most pronouncedly delayed freeze-up and showed the highest potential for carry-over effects (fig. 3c,d, S12-S13). As the frequency of extreme summer precipitation events in the Arctic is anticipated to increase ${ }^{16}$, it is important that their effects on permafrost dynamics are accounted for in projections of future permafrost degradation. Our representation of soil thermal hydrology and advective heat transfer from infiltrating rain in global land surface models.

\section{Implications for thermal hydrological modelling of permafrost soils}

Using state-of-the-art numerical modelling of soil thermal hydrology, we were able to support field-observed effects with mechanistic insight into the effects of extreme summer precipitation on soil thermal dynamics. Our model parametrization adequately represented field-measured permafrost thaw dynamics (fig. 2) and soil temperatures and moisture content (fig. S7). Still, modelled differences in thaw depth under increased precipitation and carry-over effects were conservative compared to those measured experimentally. This may be a result of overestimation of evaporative fluxes and resulting cooling (fig. S9-S10). The model indicates substantial evaporative topsoil cooling (fig. S6, fig. S12-S13), which was not as evident from field measurements (fig. 
263 potential effects of vegetation (e.g. transpiration, retention of moisture in moss tissue, canopy shading and surface turbulence $)^{12,35,36}$, which may also explain the smaller effect of precipitation in model results compared to field results ${ }^{15}$. As future changes in Arctic vegetation are expected to alter the surface energy budget and thermal properties of permafrost soils ${ }^{12}$, expansion of soil thermal hydrology models to include canopy processes is recommended.

Lastly, landscape heterogeneity causes a wide range of soil hydrothermal properties, which can strongly control thaw dynamics and their response to climate change ${ }^{12,13,33,37}$. This was also evident from the fairly wide range of field-observed thaw depths, temperature and moisture conditions (fig. 1c-e, S4-S5). Our onedimensional numerical model only considers averaged site conditions and behaviour, leading to potential inaccuracies and a disregard for spatial heterogeneity of effects. Extension to 3D numerical models ${ }^{37}$ can be used to account for such nuances if sufficient spatially distributed field data are available.

The identified impact of summer precipitation on permafrost thaw dynamics suggests increased ecosystem change and feedback to climate in summers that are both warm and wet. With persistent Arctic warming and anticipated increases in summer precipitation extremes ${ }^{17}$, permafrost may degrade and disappear faster than is currently anticipated based on temperature changes alone. This may hold true especially in ice-rich permafrost, where enhanced thaw following combined warming and precipitation extremes can result in soil subsidence due to melting of abundant ground ice (thermokarst). Thermokarst triggers local feedbacks such as concentration of lateral flow, accumulation of water in the soil profile (fig. 1d \& S6b) and accumulation 
287 of snow in depressions in winter, accelerating permafrost degradation over longer timescales ${ }^{30,38}$. Extreme summer drought in contrast, may protect permafrost from high summer temperatures due to stronger thermal insulation of dry soil and reduced heat inputs from infiltration of rainwater.

Apart from deeper thaw, model results indicate delayed freeze-up following summer precipitation extremes, resulting in larger volumes of unfrozen soil becoming subject to decomposition and greenhouse gas (GHG) release over longer time periods. Freeze-up delay was largest under late summer precipitation extremes (fig. 3d). Due to temperature increases, an increasing proportion of autumn precipitation will fall as rain rather than snow in the future ${ }^{17,18}$, likely further delaying freeze-up. Methane emissions during freeze-up may constitute as much as $20 \%$ of total annual methane emissions $^{39}$. Additionally, warmer and wetter conditions in subsoils may further promote methane production ${ }^{22,40}$, while methane oxidation may be reduced in wetter and colder (fig. S12-S13) topsoils ${ }^{34}$. As a result, methane emissions may increase much more than would be anticipated based on temperature increases alone. Conversely, cooling of the topsoil and soil wetting can reduce $\mathrm{CO}_{2}$ emissions through reduced ecosystem respiration ${ }^{34}$. In contrast, extreme summer precipitation events and associated cloudiness have also been observed to substantially reduce $\mathrm{CO}_{2}$ uptake in Arctic ecosystems ${ }^{41}$. Effects of cloudiness were not accounted for using our methodology as irrigation was performed regardless of cloud cover and precipitation scenarios were modified without adjusting incoming shortwave radiation.

Lastly, impacts of precipitation-induced active layer deepening may be highly ecosystem-specific. North-eastern Siberian tundra ecosystems are adjusted to low precipitation levels and generally have shallow active layers ${ }^{42}$, making them potentially 
sensitive to vegetation shifts under wetting and active layer deepening. Soil wetting

312 following thermokarst can promote shifts from shrub- to graminoid dominated systems $^{29,43}$, although moderate wetting may also promote shrub growth through alleviation of previously water-limited conditions ${ }^{44,45}$. Persistent deepening of the active layer following precipitation extremes can increase nutrient availability and rooting space, stimulating the growth of deeper-rooting graminoids ${ }^{46}$. However, it may also facilitate deeper infiltration or drainage ${ }^{4}$, resulting in a drying effect on longer timescales (see for instance reduced topsoil moisture in 2020, fig. 1e). Net effects of precipitation-induced permafrost thaw will likely depend strongly on the rate of permafrost thaw (gradual or abrupt) and local topography, vegetation and hydrology. A complete perspective requires holistic monitoring of the effects of summer precipitation extremes across various Arctic ecosystems and climatic zones over longer time periods.

\section{Conclusion}

We showed that extreme summer precipitation can enhance permafrost thaw for multiple years. The magnitude of this effect depends strongly on concurrent summer temperatures. We recommend that future research studies variability in the response of permafrost to increased summer precipitation across a wide variety of site conditions. Our combination of field irrigation experiments, monitoring and permafrost modelling proved to be a valuable approach to do so.

\section{Methods}


We studied the effects of increased summer precipitation on permafrost thaw dynamics in a drained thaw lake basin (or "alas") in the "Kytalyk" Nature Reserve in the Indigirka Lowlands in north-eastern Siberia $\left(70 \cdot 49^{\prime} \mathrm{N}, 147 \cdot 29^{\prime} \mathrm{E}\right)$ near the town of Chokurdakh (fig. 5a). Such alases are representative for a major part of coastal northeastern Siberia ${ }^{47}$. The area is characterized by a shallow active layer overlying icerich, continuous permafrost ${ }^{48}$. The mean annual temperature is $-13.5^{\circ} \mathrm{C}$, with an average July temperature of $10.0{ }^{\circ} \mathrm{C}(1945-2019)$. The mean annual precipitation is $202 \mathrm{~mm}$, of which $81 \mathrm{~mm}$ falls in summer (June, July and August) $(1945-2019)^{49,50}$. Within the study area, elevated sites such as "Yedoma" ridges and pingos are characterized by tussock-sedge (Eriophorum vaginatum) and dwarf shrub vegetation. Lower elevation areas such as alases are characterized by slightly elevated shrub patches dominated by Betula nana, lichens and mosses, interspersed with waterlogged depressions characterized by aquatic species such as Eriophorum angustifolium, Carex spp. and Sphagnum spp. ${ }^{43,51}$.

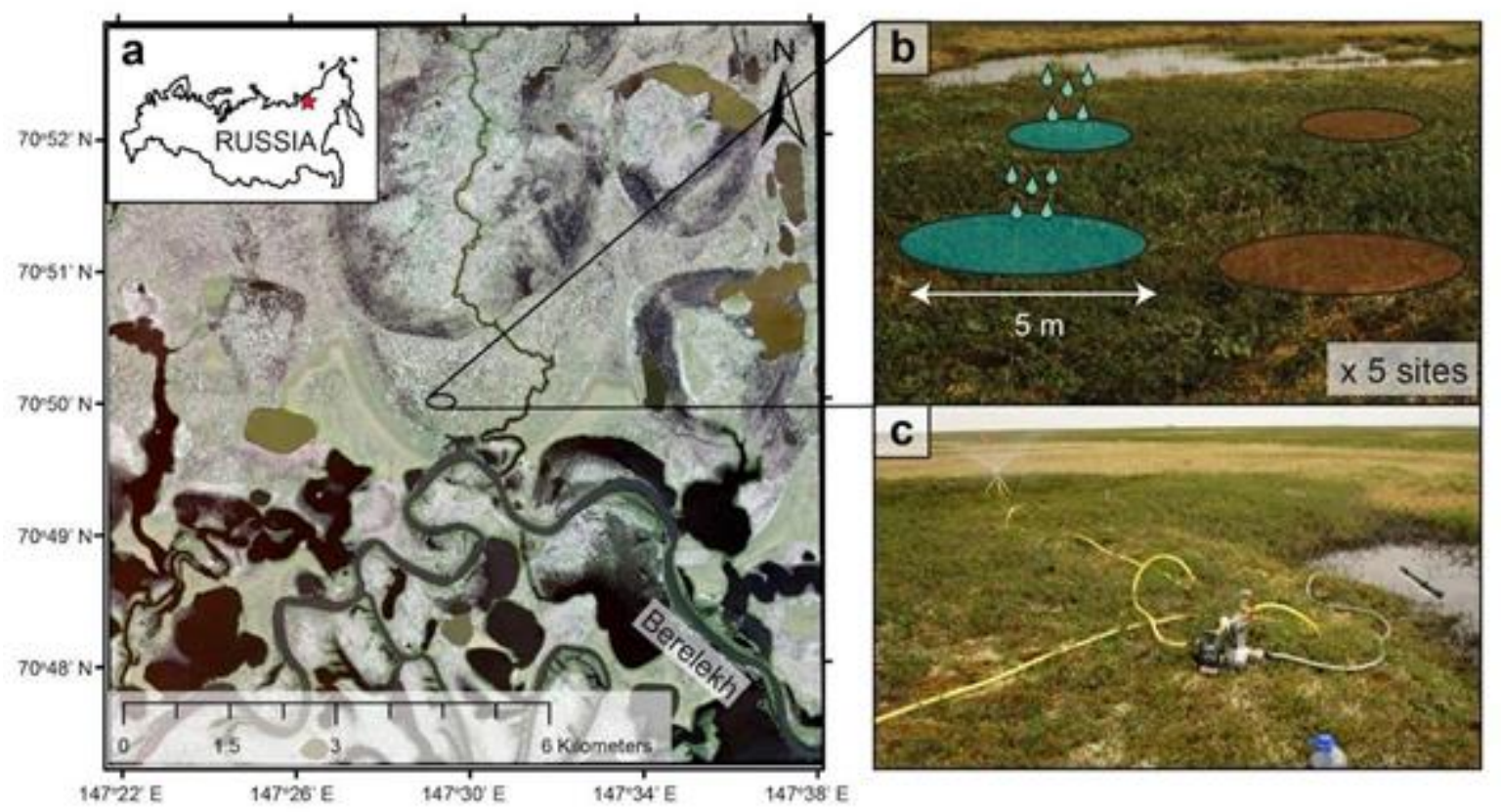

Figure 5) Study area and experimental setup. a) Our study area is situated in the 
Indigirka lowlands at the Chokurdakh Scientific Tundra Station, in a drained thaw lake basin (alas) adjoining the floodplains of the river Berelekh. Image: WorldView-2 (c) MAXAR 2019. b) In this alas, 5 sites were selected in shrub patches within 5 to $10 \mathrm{~m}$ distance from a thaw pond. In each site, 4 circular plots were set out: 2 irrigated plots (blue) and 2 control plots (brown) each with $5 \mathrm{~m}$ diameter. Plots were at least $5 \mathrm{~m}$ apart. c) The irrigation system consisted of a filter tube and motor pump which simultaneously irrigated the 2 irrigated plots per site via hoses with a length of $10 \mathrm{~m}$ and sprinklers.

\section{Experimental Design}

We set out 20 circular plots of $5 \mathrm{~m}$ diameter in five clusters of four (two irrigation, two control), located in five dwarf shrub dominated tundra patches in early summer 2018. Clusters were situated next to ponds that provided water for irrigation (fig. 5b). Clusters were around 50 to 100 meters apart and plots within clusters were at least five meters apart. We installed a PVC well in the centre of each plot to monitor the water table. Prior to irrigation, we measured thaw depth and topsoil volumetric moisture content in nine locations per plot: eight points along the perimeter of the plot at $1 \mathrm{~m}$ distance from the plot edge, and one in the centre. We visually assessed cover of the main plant species and variation in microtopography and assigned plots to pairs within clusters based on similarity in thaw depth, water table, soil moisture, vegetation composition and microtopography. Plots from pairs were randomly assigned to irrigation and control, although in a few cases the length of the hoses of the irrigation system dictated the subdivision. No significant differences were evident in thaw depth, water table or soil moisture prior to irrigation (table S3-S7). Over the period of July 6th to August 2nd 2018, we supplied $100 \mathrm{~mm}$ of irrigation to all irrigation plots and no irrigation to control 
plots using a motor pump (fig. 5c). Irrigation water was similar to rainwater in terms of chemical composition and temperature (Supplementary Methods I). We set the amount of irrigation to mimic the extremely wet summer of $2011(191 \mathrm{~mm}$ vs. $81 \mathrm{~mm}$ average in June-August ${ }^{30}$ ). We irrigated plots on an approximately biweekly basis in amounts of 10 or $15 \mathrm{~mm}$ with an application rate of $25 \mathrm{~mm}$ per hour. During the summers of 2018,2019 and 2020 , we repeated measurements of thaw depth, water table and topsoil volumetric moisture content at regular intervals. In eight plots (four irrigation, four control), we installed temperature and moisture loggers at $5 \mathrm{~cm}$ and $20 \mathrm{~cm}$ depth. Description of all measurements and equipment is available in Supplementary Methods I.

\section{Field Data Analysis}

We tested treatment (factor; irrigation or control) and measurement date (factor) and their interaction for significant effects on field-measured thaw depths, water tables and topsoil volumetric moisture content using mixed effects models. To account for repeated measurement in a nested set-up, we used plot number as a random effect and tested for significance of random intercepts and slopes on a full model with interaction using likelihood ratio tests (LRTs). The significance of fixed effects was assessed using F-tests with Kenward-Rogers approximation of degrees of freedom on nested models. The optimal model structure was determined using backwards selection based on predictor p-values, Akaike's Information Criterion (AIC), normality and homoscedasticity of residuals and absence of patterns of residuals against random factors and fitted values. We allowed for transformation of dependent variables and addition of zero-inflation components to improve residual diagnostics. We performed all statistical analysis in $\mathrm{R}$ version 3.5.1 using the Ime4 package ${ }^{52}$. An 
extensive description of the procedures for statistical analysis is available in Supplementary Methods II.

We used the Advanced Terrestrial Simulator (ATS) ${ }^{31}$ version 0.88 to (1) support the field experiment with mechanistic insight and (2) to explore the temperature sensitivity of rainfall effects using several precipitation and temperature scenarios. ATS is a fully coupled surface-subsurface thermal hydrology model, configured for permafrost applications ${ }^{53}$. It couples the surface energy balance and snow dynamics with a subsurface thermal hydrology scheme to represent three-phase freeze- and thaw cycles accounting for moisture migration. To run the model, atmospheric data on air temperature, precipitation, incoming shortwave radiation, relative humidity and wind speed is required. Except for incoming shortwave radiation, a time series from January $1^{\text {st }} 1966$ to July 31 st 2020 for all these values was available for Chokurdakh (WMO station code $21649,30 \mathrm{~km}$ northwest of the study site) from the All-Russia Research Institute of Hydrometeorological Information - World Data Centre ${ }^{50}$. Incoming shortwave radiation was retrieved from ERA5 reanalysis data ${ }^{54}$. We conditioned a predefined set of model hydrological parameters and thermal parameters (see table S8) for each layer by maximizing the fit of modelled thaw depths with the field measurement series. We used Nash-Sutcliffe Efficiency (NSE) to quantify the extent to which the modelled depth of the $0^{\circ} \mathrm{C}$ isotherm (the depth at which the permafrost table is situated) followed the field measured thaw depths. In addition, modelled soil moisture and soil temperature at $5 \mathrm{~cm}$ and $20 \mathrm{~cm}$ depth were compared visually to logger measurements. An extensive description of the model calibration procedure 
and resulting fits with field measurement series is available in Supplementary Methods

422 III and IV.

423 We used the conditioned model parametrization to analyse various summer 424 precipitation scenarios for one summer, followed by two years of averaged conditions. 425 We established a baseline scenario with daily precipitation and temperature based on 426 averaged forcing conditions (1979-2018) and several scenarios with varied amounts 427 and timing of summer precipitation based on frequency-intensity distributions of daily 428 precipitation from the Chokurdakh record ${ }^{50}$. We simulated years with high (70th - 80th percentile of total JJA precipitation) and extreme precipitation (95th - 100th percentile of total JJA precipitation). Furthermore, four scenarios with 80 additional $\mathrm{mm}$ of 431 precipitation only added in June, July, August and September, respectively. We complement the precipitation scenarios by adding two temperature scenarios simulating a summer of average temperature (JJA mean $\left.7.9^{\circ} \mathrm{C}\right)$, and a very warm summer based on the 95th - 100th percentile of mean summer temperature (JJA mean $\left.10.6^{\circ} \mathrm{C}\right)$. We compared the active layer thickness (ALT, calculated as the maximum end-of-season depth of the $0^{\circ} \mathrm{C}$ isotherm) and timing of complete freeze-up among 437 the different summer precipitation scenarios. An elaborate description of scenario definition is available in Supplementary Methods V. 


\section{References}

1 Biskaborn, B. K. et al. Permafrost is warming at a global scale. Nature communications 10, 1-11 (2019).

2 Farquharson, L. M. et al. Climate change drives widespread and rapid thermokarst development in very cold permafrost in the Canadian High Arctic. Geophysical Research Letters 46, 6681-6689 (2019).

3 Fraser, R. H. et al. Climate sensitivity of high Arctic permafrost terrain demonstrated by widespread ice-wedge thermokarst on Banks Island. Remote Sensing 10, 954 (2018).

$4 \quad$ Liljedahl, A. K. et al. Pan-Arctic ice-wedge degradation in warming permafrost and its influence on tundra hydrology. Nature Geoscience 9, 312 (2016). Shiklomanov, N. I., Streletskiy, D. A. \& Nelson, F. E. in Proc. 10th Int. Conf. on Permafrost. 377-382.

6 Kokelj, S. V., Lantz, T. C., Tunnicliffe, J., Segal, R. \& Lacelle, D. Climatedriven thaw of permafrost preserved glacial landscapes, northwestern Canada. Geology 45, 371-374 (2017).

7 Meredith, M. et al. (ed D.C. Roberts [H.-O. Pörtner, V. Masson-Delmotte, P. Zhai, M. Tignor, E. Poloczanska, K. Mintenbeck, A. Alegría, M. Nicolai, A. Okem, J. Petzold, B. Rama, N.M. Weyer (eds.)]. ) (2019).

8 Chadburn, S. et al. in Supplement to: Chadburn, S et al. (2017): An observation-based constraint on permafrost loss as a function of global warming. Nature Climate Change, https://doi.org/10.1038/nclimate3262 (PANGAEA, 2017).

9 Slater, A. G. \& Lawrence, D. M. Diagnosing present and future permafrost from climate models. Journal of Climate 26, 5608-5623 (2013).

10 Nitzbon, J. et al. Fast response of cold ice-rich permafrost in northeast Siberia to a warming climate. Nature Communications 11, 1-11 (2020).

11 McGuire, A. D. et al. Dependence of the evolution of carbon dynamics in the northern permafrost region on the trajectory of climate change. Proceedings of the National Academy of Sciences 115, 3882-3887 (2018).

12 Loranty, M. M. et al. Reviews and syntheses: Changing ecosystem influences on soil thermal regimes in northern high-latitude permafrost regions.

Biogeosciences 15, 5287-5313 (2018).

13 Atchley, A. L., Coon, E. T., Painter, S. L., Harp, D. R. \& Wilson, C. J. Influences and interactions of inundation, peat, and snow on active layer thickness. Geophysical Research Letters 43, 5116-5123 (2016).

14 Romanovsky, V. E., Smith, S. L. \& Christiansen, H. H. Permafrost thermal state in the polar Northern Hemisphere during the international polar year 2007-2009: a synthesis. Permafrost and Periglacial processes 21, 106-116 (2010).

15 Mekonnen, Z. A., Riley, W. J., Grant, R. F. \& Romanovsky, V. E. Changes in precipitation and air temperature contribute comparably to permafrost degradation in a warmer climate. Environmental Research Letters 16, 024008, doi:10.1088/1748-9326/abc444 (2021).

16 Bintanja, R. et al. Strong future increases in Arctic precipitation variability linked to poleward moisture transport. Science advances 6, eaax6869 (2020).

17 Bintanja, R. \& Selten, F. Future increases in Arctic precipitation linked to local evaporation and sea-ice retreat. Nature 509, 479-482 (2014). 
18 Bintanja, R. \& Andry, O. Towards a rain-dominated Arctic. Nature Climate Change 7, 263-267 (2017).

19 Douglas, T. A., Turetsky, M. R. \& Koven, C. D. Increased rainfall stimulates permafrost thaw across a variety of Interior Alaskan boreal ecosystems. npj Climate and Atmospheric Science 3, 1-7 (2020).

20 Luo, D., Jin, H., Bense, V. F., Jin, X. \& Li, X. Hydrothermal processes of nearsurface warm permafrost in response to strong precipitation events in the Headwater Area of the Yellow River, Tibetan Plateau. Geoderma 376, 114531 (2020).

21 lijima, Y. et al. Abrupt increases in soil temperatures following increased precipitation in a permafrost region, central Lena River basin, Russia.

Permafrost and Periglacial Processes 21, 30-41 (2010).

22 Neumann, R. B. et al. Warming effects of spring rainfall increase methane emissions from thawing permafrost. Geophysical Research Letters 46, 13931401 (2019).

23 Hinkel, K., Paetzold, F., Nelson, F. \& Bockheim, J. Patterns of soil temperature and moisture in the active layer and upper permafrost at Barrow, Alaska: 1993-1999. Global and Planetary Change 29, 293-309 (2001).

24 Farouki, O. T. Thermal properties of soils. (COLD REGIONS RESEARCH AND ENGINEERING LAB HANOVER NH, 1981).

25 Subin, Z. M. et al. Effects of soil moisture on the responses of soil temperatures to climate change in cold regions. Journal of climate 26,3139 3158 (2013).

26 Zhu, X. et al. Impacts of summer extreme precipitation events on the hydrothermal dynamics of the active layer in the Tanggula permafrost region on the Qinghai-Tibetan plateau. Journal of Geophysical Research: Atmospheres 122, 11,549-511,567 (2017).

27 Shur, Y., Hinkel, K. M. \& Nelson, F. E. The transient layer: implications for geocryology and climate-change science. Permafrost and Periglacial Processes 16, 5-17 (2005).

28 Olefeldt, D. et al. Circumpolar distribution and carbon storage of thermokarst landscapes. Nature communications 7, 13043 (2016).

29 van der Kolk, H.-J., Heijmans, M. M., van Huissteden, J., Pullens, J. W. \& Berendse, F. Potential Arctic tundra vegetation shifts in response to changing temperature, precipitation and permafrost thaw. Biogeosciences 13, 62296245 (2016).

30 Nauta, A. L. et al. Permafrost collapse after shrub removal shifts tundra ecosystem to a methane source. Nature Climate Change 5, 67 (2015).

31 Coon, E. et al. Advanced Terrestrial Simulator. (2019).

32 Iwahana, G. et al. Influence of forest clear-cutting on the thermal and hydrological regime of the active layer near Yakutsk, eastern Siberia. Journal of Geophysical Research: Biogeosciences 110 (2005).

33 Abramov, A. et al. Two decades of active layer thickness monitoring in northeastern Asia. Polar Geography, 1-17, doi:10.1080/1088937X.2019.1648581 (2019).

34 Göckede, M. et al. Negative feedback processes following drainage slow down permafrost degradation. Global change biology 25, 3254-3266 (2019).

35 van Huissteden, J. Thawing Permafrost: Permafrost Carbon in a Warming Arctic. (Springer Nature, 2020). 
36 Blok, D. et al. Shrub expansion may reduce summer permafrost thaw in Siberian tundra. Global Change Biology 16, 1296-1305 (2010).

37 Abolt, C. J., Young, M. H., Atchley, A. L. \& Harp, D. R. Microtopographic control on the ground thermal regime in ice wedge polygons. The Cryosphere (Online) 12 (2018).

38 Jorgenson, M., Shur, Y. L. \& Pullman, E. R. Abrupt increase in permafrost degradation in Arctic Alaska. Geophysical Research Letters 33 (2006).

39 Bao, T., Xu, X., Jia, G., Billesbach, D. P. \& Sullivan, R. C. Much stronger tundra methane emissions during autumn-freeze than spring-thaw. Global Change Biology (2020).

40 Turetsky, M. R. et al. A synthesis of methane emissions from 71 northern, temperate, and subtropical wetlands. Global change biology 20, 2183-2197 (2014).

41 Christensen, T. et al. Multiple Ecosystem Effects of Extreme Weather Events in the Arctic. Ecosystems (2020).

42 Fujinami, H., Yasunari, T. \& Watanabe, T. Trend and interannual variation in summer precipitation in eastern Siberia in recent decades. International Journal of Climatology 36, 355-368 (2016).

43 Magnússon, R. Í. et al. Rapid vegetation succession and coupled permafrost dynamics in Arctic thaw ponds in the Siberian lowland tundra. Journal of Geophysical Research: Biogeosciences, e2019JG005618 (2020).

44 Ackerman, D., Griffin, D., Hobbie, S. E. \& Finlay, J. C. Arctic shrub growth trajectories differ across soil moisture levels. Global Change Biology 23, 4294-4302 (2017).

45 Opała-Owczarek, M. et al. The influence of abiotic factors on the growth of two vascular plant species (Saxifraga oppositifolia and Salix polaris) in the High Arctic. Catena 163, 219-232 (2018).

46 Wang, P. et al. Above-and below-ground responses of four tundra plant functional types to deep soil heating and surface soil fertilization. Journal of Ecology 105, 947-957 (2017).

47 Fedorov, A. N. et al. Permafrost-Landscape Map of the Republic of Sakha (Yakutia) on a Scale 1: 1,500,000. Geosciences 8, 465 (2018).

48 Van Huissteden, J., Maximov, T. \& Dolman, A. High methane flux from an arctic floodplain (Indigirka lowlands, eastern Siberia). Journal of Geophysical Research: Biogeosciences 110 (2005).

49 Trouet, V. \& Van Oldenborgh, G. J. KNMI Climate Explorer: a web-based research tool for high-resolution paleoclimatology. Tree-Ring Research 69, 314 (2013).

50 RIHMI-WDC. (2020).

51 Siewert, M. B. et al. Comparing carbon storage of Siberian tundra and taiga permafrost ecosystems at very high spatial resolution. Journal of Geophysical Research: Biogeosciences 120, 1973-1994 (2015).

52 Bates, D., Mächler, M., Bolker, B. \& Walker, S. Fitting linear mixed-effects models using Ime4. arXiv preprint arXiv:1406.5823 (2014).

53 Painter, S. L. et al. Integrated surface/subsurface permafrost thermal hydrology: Model formulation and proof-of-concept simulations. Water Resources Research 52, 6062-6077 (2016).

54 Hersbach, $\mathrm{H}$. et al. The ERA5 global reanalysis. Quarterly Journal of the Royal Meteorological Society 146, 1999-2049 (2020). 


\section{Supplementary Files}

This is a list of supplementary files associated with this preprint. Click to download.

- NCCTundralrrigationMagnussonSuppl.pdf 